\title{
ESTUDO DA QUALIDADE DA ÁGUA UTILIZADA EM HEMODIÁLISE
}

\author{
D. R. PINHEIRO ${ }^{1}$, A. P. PINHEIRO ${ }^{2}$ e M. C. MARTELLI ${ }^{3}$ \\ ${ }^{1}$ Universidade Federal do Pará, Programa de Pós-Graduação em Engenharia Química \\ ${ }^{2}$ Universidade Federal do Pará, Faculdade de Engenharia Química \\ ${ }^{3}$ Universidade Federal do Pará, Faculdade de Engenharia Química; Programa de Pós-Graduação em \\ Engenharia Química \\ E-mail para contato: darllandorosario@gmail.com
}

\begin{abstract}
RESUMO - A água é uma das substâncias existentes na Terra de maior importância para os seres que habitam este planeta, por participar intimamente das reações metabólicas que ocorrem no organismo humano. Porém, para pessoas com insuficiência renal, a água necessita de um tratamento específico para ser utilizada em procedimento de purificação extracorpórea do sangue, a hemodiálise. Este trabalho avalia a qualidade da água utilizada em hemodiálise na Fundação Pública Estadual Hospital de Clínicas Gaspar Vianna (FPEHCGV) além de comparar os resultados das análises físico-químicas obtidas pelo Processo de Osmose Reversa (OR) com o Processo de Ultrafiltração (UF) analisando os fatores que influenciam a UF, tais como: compactação da membrana; permeabilidade hidráulica; e incrustação (fouling), para verificar/confirmar a maior seletividade do processo de OR. Os resultados demonstraram que a qualidade da água utilizada para procedimento dialítico está em conformidade com a RDC 154/ANVISA, porém a água de abastecimento do Serviço de Terapia Renal Substitutiva (STRS) da FPEHCGV está com valores de alumínio acima do estabelecido pela portaria 2914 do Ministério da Saúde (MS).
\end{abstract}

\section{INTRODUÇÃO}

Antigamente, por volta da década de 70, acreditava-se que a água, dentro dos parâmetros físicoquímicos e bacteriológicos para um padrão de potabilidade estabelecido para a época, poderia ser utilizada nas sessões de hemodiálise. Porém, com o aumento do número de pacientes em tratamento dialítico, pesquisadores relacionaram as mais diversas reações que ocorriam nos pacientes durante os procedimentos dialíticos realizados, com a água utilizada. Concluíram, então, que esse padrão de potabilidade de água para consumo humano não poderia ser tomado como critério seguro para ser utilizado em pessoas submetidas ao tratamento dialítico (SILVA et al, 1996). Apesar da água de abastecimento público que chega ao hospital ou unidade de saúde ser potável para consumo humano, ela é inadequada para uso em hemodiálise ou para outros fins especiais (hemodinâmica, lavagem de cateteres, preparação de dietas enterais, etc), uma vez que a água potável contém um leque de 
elementos químicos dissolvidos e, dependendo da origem da água ou da rota percorrida nas tubulações externas, pode conter também material orgânico, sais minerais, metais pesados, microorganismos, endotoxinas ou microcistinas produzidas por algas, devendo esta água ser submetida a novo tratamento antes de sua utilização (PEGORARO, 2005). Por isso há a necessidade de se realizar um tratamento específico da água, para retirada de substâncias maléficas à saúde desses pacientes.

Neste sentido este trabalho teve por objetivo geral avaliar a qualidade da água utilizada em hemodiálise pela Fundação Pública Estadual Hospital de Clínicas Gaspar Vianna (FPEHCGV) estudando a compatibilidade entre as caracterizações físico-químicas da água pós processo de osmose reversa (OR) utilizada pela FPEHCGV e da água pós processo de ultrafiltração (UF) de bancada. Avaliaram-se também os parâmetros físico-químicos da água que abastece a FPEHCGV, de acordo com o estabelecido pela Portaria 2914 do Ministério da Saúde e seus anexos e o desempenho do Processo de Separação por Membranas (Ultrafiltração): compactação da membrana; incrustação (fouling) e permeabilidade hidráulica.

\section{MATERIAIS E MÉTODOS}

Para o presente estudo foi utilizada como matéria prima a água de entrada na estação de tratamento para hemodiálise no STRS/FPEHCGV (figura 1), situado em Belém (PA). Parte deste material foi caracterizado de acordo com o disposto na portaria 2914 do MS para água potável. As demais amostras foram tratadas no sistema de separação por membranas (ultrafiltração), para se avaliar comparativamente as características físico-químicas entre o permeado oriundo da UF em relação aos resultados obtidos pelo hospital referentes ao processo de osmose reversa que a Fundação utiliza atualmente, tendo como referência os parâmetros estabelecidos pela RDC 154 (ANVISA).

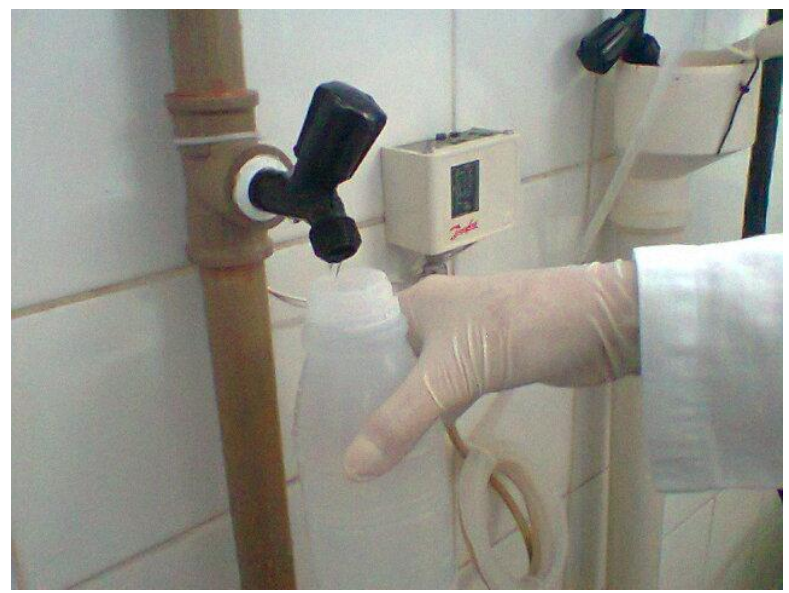

Figura 1- Coleta de material. Fonte: O Autor

\subsection{Equipamento, módulo de UF e permeabilidade hidráulica}

O módulo de UF e equipamento de bancada de MF, UF e NF utilizados nos experimentos foram fabricados pela PAM Membranas Ltda (Rio de Janeiro, RJ). O módulo de UF, modelo 0029 foi 
construído em PVC soldável, com diâmetro externo de $20 \mathrm{~mm}$, comprimento útil de $270 \mathrm{~mm}$, área de permeação de $0,015 \mathrm{~m}^{2}$, densidade de empacotamento de $300 \mathrm{~m}^{2} / \mathrm{m}^{3}$, pressão e temperatura máxima de operação de 5,0 bar e $50{ }^{\circ} \mathrm{C}$, fabricado com poli (sulfona) e pH na faixa de trabalho de 2-13. Durante a manipulação do equipamento foram realizadas a compactação da membrana e o estudo do fouling, conforme sequência operacional estabelecida no processo que foi adaptado a partir do manual do equipamento além de realizar ensaios de permeabilidade para avaliar a variação de fluxo do permeado relacionado à variação de pressão. Para isto alterou-se a pressão de operação do equipamento, em sequência de pressão inversa - 4, 3, 2 e 1 bar-plotando-se o gráfico resultante, para demonstrar esta relação entre fluxo de permeado e pressão de operação.

\subsection{Análises físico-químicas}

Os parâmetros analisados tanto para água potável quanto para água permeada depois do processo de UF foram: nitrato, alumínio, sódio, cálcio, magnésio, potássio, bário, sulfato, chumbo, cádmio e cromo. Há outros parâmetros físico-químicos a serem avaliados para este tipo de material, porém o presente estudo dedicou-se a avaliar somente as espécies químicas listadas anteriormente, pois são as espécies presentes em maiores concentrações nas águas de abastecimento local. Como o trabalho concentrou-se no estudo físico-químico, as avaliações bacteriológicas não foram realizadas. Parte do volume total de água coletada na FPEHCGV foi analisada no laboratório de análise físicoquímica do Instituto Evandro Chagas (IEC), enquanto que o volume restante foi processado no equipamento de MF/UF/NF da UFPA, sendo este volume pós-processo, analisado também no IEC. Os resultados obtidos dessas análises foram comparados com as referências estabelecidas pela RDC 154 (ANVISA) e, também, comparados ao resultado obtido a partir de análise realizada em processo de tratamento por osmose reversa, procedimento utilizado pela FPEHCGV, realizada pela empresa Conágua Ambiental, localizada em Goiânia.

As variáveis nitrato e sulfato foram determinados por espectrofotometria no equipamento de Cromatografia de íons. Os metais alumínio $(\mathrm{Al})$, bário $(\mathrm{Ba})$, cromo $(\mathrm{Cr})$, cobre $(\mathrm{Cu})$ foram analisados por Espectrometria de Emissão Ótica com Plasma Induzido (ICP OES), no equipamento ICP-OES Modelo Vista- MPX CCD simultâneo, axial da VARIAN@ com um sistema de amostragem automático (SPS- 5). O controle das condições operacionais do ICP-OES foi realizada com o software ICPExpert Vista ${ }^{\circledR}$, para edição dos métodos analíticos e controle das condições operacionais. Para a verificação da qualidade da água que abastece o STRS/FPEHCGV, foi coletada uma amostra de 500 ml e posteriormente levada ao Laboratório Analítico, localizado em Belém, para verificação dos parâmetros físico-químicos conforme os limites estabelecidos pela Portaria 2914/MS. Para o levantamento de substâncias químicas e organolépticas, tomaram-se como base os resultados das análises de água potável fornecidos pelo IEC e estes foram comparados com os parâmetros estabelecidos pela Portaria 2914/MS. Os métodos analíticos empregados para a determinação dos parâmetros físico-químicos obedeceram aos procedimentos e recomendações descritas no Standard Methods for Examination of Water and Wastewater (APHA/ AWWA/WEF, 2005). 


\section{RESULTADOS E DISCUSSÃO}

\subsection{Compactação da Membrana}

A compactação da membrana foi realizada operando-se o equipamento com a pressão máxima de operação, 5 bar, medindo-se o fluxo de permeado até que este ficasse constante. O gráfico 1 mostra a curva de compactação para o módulo de UF utilizado no experimento. O tempo de compactação foi de aproximadamente 22 minutos com um fator de redução de fluxo de aproximadamente $36,25 \%$, calculado a partir da relação entre os fluxos final $\left(500 \mathrm{~L} \cdot \mathrm{m}^{-2} \cdot \mathrm{h}^{-1}\right)$ e inicial $\left(784,3137 \mathrm{~L} \cdot \mathrm{m}^{-2} \cdot \mathrm{h}^{-1}\right)$.

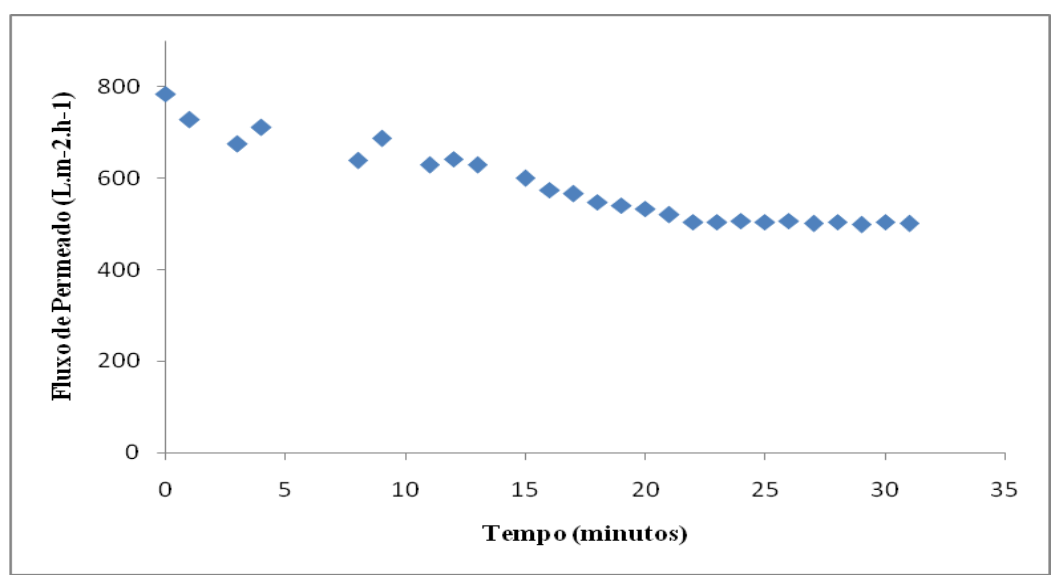

Gráfico 1 - Compactação da Membrana de UF 0029

\subsection{Incrustação (fouling)}

Para o estudo do efeito do fouling foi utilizada a água coletada e a colocou no sistema, em operação contínua, com pressão de 5 bar, analisando-se o fluxo de permeado durante 30 minutos. $\mathrm{O}$ gráfico 2 descreve o efeito do fouling. Como pode ser observado no gráfico ocorreu uma redução no fluxo de permeado, porém essa diminuição foi pequena, pois o material utilizado é água potável e teoricamente não contém elementos que venham a diminuir drasticamente o fluxo de permeado.

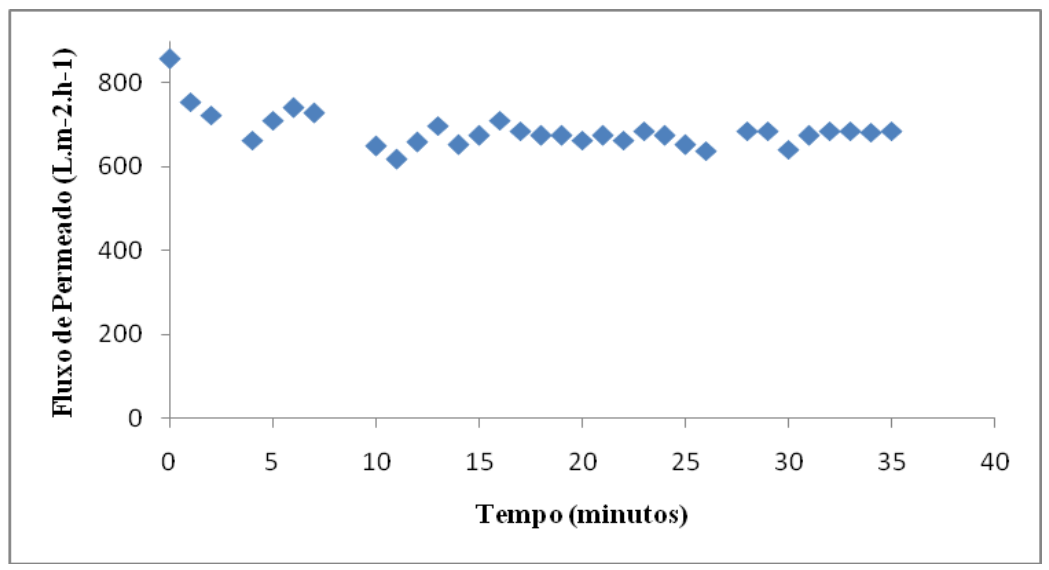

Gráfico 2 - Efeito do Fouling 


\subsection{Permeabilidade hidráulica}

O valor da permeabilidade hidráulica é calculado como sendo o coeficiente angular do gráfico 3, portanto será de $119,39 \mathrm{~L} \cdot \mathrm{m}^{-2} \cdot \mathrm{h}^{-1} \cdot \mathrm{bar}^{-1}$. A dependência que o fluxo de permeado tem com a pressão de operação está demonstrada no gráfico 3.

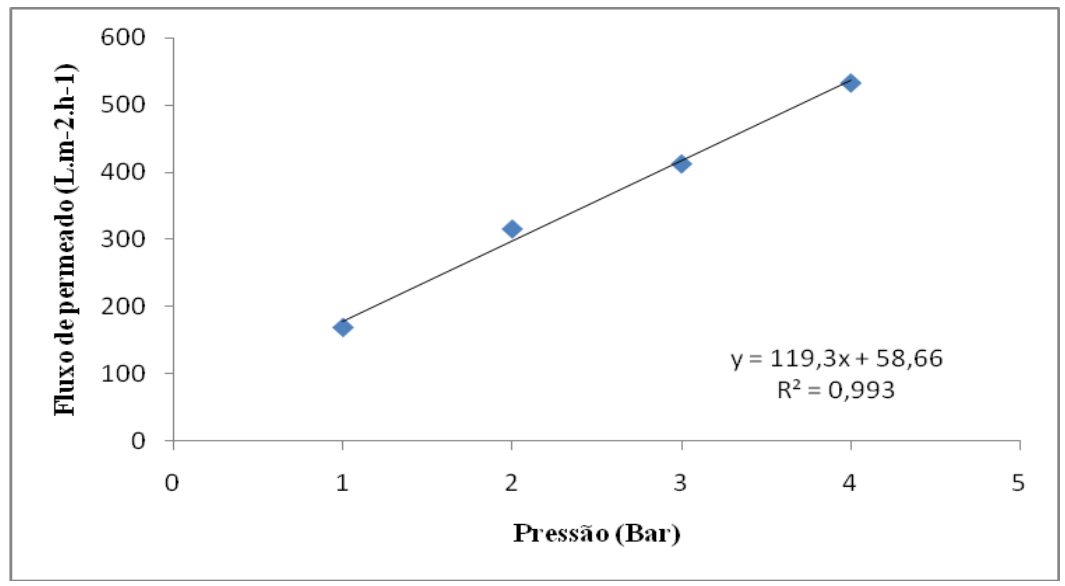

Gráfico 3 - Permeabilidade Hidráulica

Todos os resultados (compactação; incrustação; permeabilidade) estão dentro da normalidade segundo estudo realizado por Costa et al, 2012.

\subsection{Análise físico-química da água não tratada e tratada no equipamento de MF/UF/NF}

Na tabela 1 estão apresentadas as análises físico-químicas da água bruta e permeado no equipamento de MF/UF/NF, juntamente com os parâmetros estabelecidos pela RDC 154 da ANVISA.

Tabela 1 - Resultados da análise físico-química

\begin{tabular}{lccc|cc}
\hline & $\begin{array}{c}\text { RDC } \\
154 \\
(\mathrm{mg} / \mathrm{L})\end{array}$ & $\begin{array}{c}\text { AMOSTRA1 } \\
(\mathrm{mg} / \mathrm{L})\end{array}$ & $\begin{array}{c}\text { PERMEADO } \\
(\mathrm{mg} / \mathrm{L})\end{array}$ & $\begin{array}{c}\text { AMOSTRA 2 } \\
(\mathrm{mg} / \mathrm{L})\end{array}$ & $\begin{array}{c}\text { PERMEADO } \\
(\mathrm{mg} / \mathrm{L})\end{array}$ \\
Nitrato & 2 & 1,0828 & 1,0641 & 1,1793 & 1,1770 \\
Alumínio & 0,01 & 0,2772 & $<\mathrm{LD}$ & 0,6547 & $<\mathrm{LD}$ \\
Sódio & 70 & 10,7450 & 9,9218 & 10,3737 & 10,2923 \\
Cálcio & 2 & 2,7730 & 2,7385 & 2,4898 & 2,4502 \\
Magnésio & 4 & 1,3040 & 1,1826 & 0,9693 & 0,9304 \\
Potássio & 8 & 1,3688 & 1,5024 & 1,2773 & 1,2656 \\
Bário & 0,1 & 0,0099 & 0,0090 & 0,0102 & 0,0083 \\
Sulfato & 100 & 2,8331 & 2,7794 & 2,1484 & 2,1337 \\
Chumbo & 0,005 & $<\mathrm{LD}$ & $<\mathrm{LD}$ & $<\mathrm{LD}$ & $<\mathrm{LD}$ \\
Cádmio & 0,001 & $<\mathrm{LD}$ & $<\mathrm{LD}$ & $<\mathrm{LD}$ & $<\mathrm{LD}$ \\
Cromo & 0,014 & $<\mathrm{LD}$ & $<\mathrm{LD}$ & $<\mathrm{LD}$ & $<\mathrm{LD}$ \\
\hline
\end{tabular}


O elemento cálcio está acima do permitido pela RDC 154 (ANVISA) como pode ser observado na tabela acima. $\mathrm{O}$ que demonstra uma não seletividade da membrana utilizada para este componente.

\subsection{Estudo comparativo com osmose reversa}

Tabela 2 - Comparação com a osmose reversa

\begin{tabular}{lcc|cc}
\hline RDC $154(\mathrm{mg} / \mathrm{L})$ & $\begin{array}{c}\text { PERMEADO } \\
(\mathrm{mg} / \mathrm{L})\end{array}$ & $\begin{array}{c}\text { PERMEADO } \\
(\mathrm{mg} / \mathrm{L})\end{array}$ & $\begin{array}{c}\text { OSMOSE } \\
\text { REVERSA }\end{array}$ \\
\hline Nitrato & 2 & 1,0641 & 1,1770 & 0,01 \\
\hline Aluminio & 0,01 & $<\mathrm{LD}$ & $<\mathrm{LD}$ & $<0,004$ \\
Sódio & 70 & 9,9218 & 10,2923 & $<0,263$ \\
Cálcio & 2 & 2,7385 & 2,4502 & $<0,8$ \\
Magnésio & 4 & 1,1826 & 0,9304 & $<0,4$ \\
\hline Potássio & 8 & 1,5024 & 1,2656 & $<0,01$ \\
Bário & 0,1 & 0,0090 & 0,0083 & $<0,005$ \\
Sulfato & 100 & 2,7794 & 2,1337 & $<0,11$ \\
Chumbo & 0,005 & $<\mathrm{LD}$ & $<\mathrm{LD}$ & $<0,005$ \\
Cádmio & 0,001 & $<\mathrm{LD}$ & $<\mathrm{LD}$ & $<0,001$ \\
Cromo & 0,014 & $<\mathrm{LD}$ & $<\mathrm{LD}$ & $<0,005$ \\
\hline
\end{tabular}

De acordo com a tabela 2 observa-se que apesar dos valores alcançados pela ultrafiltração estarem dentro da legislação, menos a espécie química cálcio, quando comparado com os valores alcançados pelo processo de osmose reversa, a ultrafiltração torna-se menos seletiva e eficiente para retenção dos componentes estudados, o que é comprovado segundo Valentas et al, 1997.

\subsection{Avaliação da qualidade da água de abastecimento da FPEHCGV para o serviço de hemodiálise.}

Tabela 3 - Caracterização Água Potável - Laboratório Analítico

\begin{tabular}{lcc}
\hline \multicolumn{1}{c}{ PARÂMETROS } & CONCENTRAÇÃO & PORTARIA 2914/MS \\
\hline Acidez $(\mathrm{mg} / \mathrm{L})$ & 4 & Não Padronizado \\
Alcalinidade $(\mathrm{mg} / \mathrm{L})$ & 6 & Não Padronizado \\
Cloretos $(\mathrm{mg} / \mathrm{L})$ & 82,33 & Até 250 \\
Cloro Residual $(\mathrm{mg} / \mathrm{L})$ & 0 & Max. 2 \\
Condutividade $(\mu \mathrm{S} / \mathrm{cm})$ & 301 & Não Padronizado \\
Cor aparente $(\mathrm{Pt}-\mathrm{Co} / \mathrm{L})$ & 0 & $15 \mathrm{UH}$ \\
Dureza $(\mathrm{mg} / \mathrm{L})$ & 50,7 & Até 500 \\
Ferro $(\mathrm{mg} / \mathrm{L})$ & $<0,05$ & Até 0,3 \\
Gosto & Não Objetável & Não Objetável \\
Nitrato $(\mathrm{mg} / \mathrm{L} \mathrm{N})$ & 0,9 & Até 10
\end{tabular}


Tabela 4 - Caracterização Água Potável - Laboratório Analítico - Continuação

\begin{tabular}{|c|c|c|}
\hline PARÂMETROS & CONCENTRAÇÃO & PORTARIA 2914/MS \\
\hline Nitrito $(\mathrm{mg} / \mathrm{L} \mathrm{N})$ & 0,003 & Até 1 \\
\hline $\begin{array}{l}\text { Nitrogênio Amoniacal }(\mathrm{mg} / \mathrm{L} \\
\mathrm{N})\end{array}$ & 0,29 & Até 1,5 \\
\hline Odor & Não Objetável & Não Objetável \\
\hline $\mathrm{pH}$ & 7,18 & 6 a 9,5 \\
\hline $\begin{array}{l}\text { Sólidos Totais Dissolvidos } \\
(\mathrm{mg} / \mathrm{L})\end{array}$ & 151 & Até 1000 \\
\hline Sulfato $(\mathrm{mg} / \mathrm{L})$ & 18 & Até 250 \\
\hline Turbidez (NTU) & 0,01 & Até 5 \\
\hline
\end{tabular}

Os resultados das análises físico-químicas da amostra apresentaram concentrações em conformidade com os limites estabelecidos na Portaria 2914/MS para água potável. Na tabela 4 estão valores obtidos para caracterização da água potável para substâncias químicas.

Tabela 5 - Caracterização elementos químicos e organolépticos de acordo com a Portaria 2914

\begin{tabular}{lcccc}
\hline PARÂMETRO & $\begin{array}{c}\text { AMOSTRA } \\
\mathbf{1}\end{array}$ & $\begin{array}{c}\text { AMOSTRA } \\
\mathbf{2}\end{array}$ & $\begin{array}{c}\text { PORTARIA } \\
\text { 2914/MS }\end{array}$ & $\begin{array}{c}\text { Limite de } \\
\text { detecção LD }\end{array}$ \\
\hline Nitrato $(\mathrm{mg} / \mathrm{L})$ & 1,0828 & 1,1793 & 10 & - \\
Aluminio $(\mathrm{mg} / \mathrm{L})$ & 0,2772 & 0,6547 & 0,2 & - \\
Fluoreto $(\mathrm{mg} / \mathrm{L})$ & 0,0090 & 0,1275 & 1,5 & - \\
Sódio $(\mathrm{mg} / \mathrm{L})$ & 10,7450 & 10,3737 & 200 & - \\
Cálcio $(\mathrm{mg} / \mathrm{L})$ & 2,7730 & 2,4898 & - & - \\
Magnésio $(\mathrm{mg} / \mathrm{L})$ & 1,3040 & 0,9693 & - & - \\
Potássio $(\mathrm{mg} / \mathrm{L})$ & 1,3688 & 1,2773 & - & - \\
Bário $(\mathrm{mg} / \mathrm{L})$ & 0,0099 & 0,0102 & 0,7 & - \\
Sulfato $(\mathrm{mg} / \mathrm{L})$ & 2,8331 & 2,1484 & 250 & - \\
Chumbo $(\mathrm{mg} / \mathrm{L})$ & $<\mathrm{LD}$ & $<\mathrm{LD}$ & 0,01 & 0,0010 \\
Cádmio $(\mathrm{mg} / \mathrm{L})$ & $<\mathrm{LD}$ & $<\mathrm{LD}$ & 0,005 & 0,0001 \\
Cromo $(\mathrm{mg} / \mathrm{L})$ & $<\mathrm{LD}$ & $<\mathrm{LD}$ & 0,05 & 0,0004 \\
\hline
\end{tabular}

Para os parâmetros analisados, o componente Alumínio está com concentração acima do valor máximo permitido pela Portaria 2914/MS, tanto para a amostra 1 quanto para a amostra 2, uma explicação para este fato é que dependendo do tipo de tratamento da água para consumo humano, operações de floculação são realizadas e são utilizados compostos de alumínios (sulfato de alumínio) como floculantes e a ocorrência de valores para alumínio acima do estipulado pela legislação sugerem problemas no controle e adição deste produto químico como material floculante, segundo Figueiredo, 2004 . 


\section{CONCLUSÃO}

A qualidade da água proveniente do abastecimento público para atender a FPEHCGV, segundo os resultados gerados mostram, de acordo com a Resolução RDC 154 que toma como base, para esta água, que os parâmetros físico-químicos estabelecidos pela Portaria 2914/ MS estão de acordo com a referida Resolução. Porém, quando foi realizado o levantamento comparativo das substâncias químicas estudadas, com os valores estipulados na Portaria 2914/ MS, observou-se que o componente alumínio apresentou valores acima do permitido. Este fato tornaria a água de abastecimento, segundo a RDC 154 e Portaria 2914/MS, imprópria para a utilização em serviços de Diálise, porém os valores da água tratada por osmose reversa mostraram-se eficientes, pois o processo de OR reduziu este valor de alumínio a níveis abaixo do limite permitido, assim como manteve os níveis dos outros elementos abaixo dos limites permitidos pela RDC 154. Os estudos realizados na membrana de UF mostraramse de acordo com resultados obtidos por outros autores citados ao longo deste trabalho.

\section{REFERÊNCIAS}

APHA, American Public Health Association; American Water Works Association (AWWA), Water Environment Federation (WEF), 2005. Standard Methods for the Examination of Water \& Wastewater

BRASIL. Agência Nacional de Vigilância Sanitária. Resolução nº 154 de 2004.

BRASIL .Ministério da Saúde. Portaria n ${ }^{\circ}$ 2914/MS de 2011.

COSTA, D.S.O.; RODRIGUES, E. C.; QUARESMA O. C., OLIVEIRA K. B.; MACÊDO E. N. Tratamento de Água do Igarapé do Tucunduba (Belém, Pa) Utilizando Membranas de Micro e Ultrafiltração. Congresso Brasileiro de Engenharia Química 2012

PEGORARO, Leandro Andrade. Validação de metodologia analítica aplicada ao controle da qualidade de água para hemodiálise para fins de credenciamento junto ao Inmetro. Projeto Hemotec II. Curitiba: Tecpar; Finep, 2005.

SILVA, A. M. M. et al. Revisão/atualização em diálise: água para hemodiálise. Jornal Brasileiro de Nefrologia, v. 18, n. 2, p. 180-188, 1996.

VALENTAS, K. J.; ROTSTEIN, E.; SINGH, R. P. Handbook of food engineering practice. CRC Press, New York, 1997. 